\title{
Residual circulation trajectories and transit times into the extratropical lowermost stratosphere
}

\author{
T. Birner ${ }^{1}$ and H. Bönisch ${ }^{2}$ \\ ${ }^{1}$ Department of Atmospheric Science, Colorado State University, Fort Collins, CO, USA \\ ${ }^{2}$ Institute for Atmospheric and Environmental Sciences, Goethe University Frankfurt, Frankfurt am Main, Germany \\ Received: 22 June 2010 - Published in Atmos. Chem. Phys. Discuss.: 7 July 2010 \\ Revised: 6 January 2011 - Accepted: 23 January 2011 - Published: 28 January 2011
}

\begin{abstract}
Transport into the extratropical lowermost stratosphere (LMS) can be divided into a slow part (time-scale of several months to years) associated with the globalscale stratospheric residual circulation and a fast part (timescale of days to a few months) associated with (mostly quasi-horizontal) mixing (i.e. two-way irreversible transport, including extratropical stratosphere-troposphere exchange). The stratospheric residual circulation may be considered to consist of two branches: a deep branch more strongly associated with planetary waves breaking in the middle to upper stratosphere, and a shallow branch associated with synoptic and planetary scale waves breaking in the subtropical lower stratosphere. In this study the contribution due to the stratospheric residual circulation alone to transport into the LMS is quantified using residual circulation trajectories, i.e. trajectories driven by the (time-dependent) residual mean meridional and vertical velocities. This contribution represents the advective part of the overall transport into the LMS and can be viewed as providing a background onto which the effect of mixing has to be added. Residual mean velocities are obtained from a comprehensive chemistry-climate model as well as from reanalysis data. Transit times of air traveling from the tropical tropopause to the LMS along the residual circulation streamfunction are evaluated and compared to recent mean age of air estimates. A time-scale separation with much smaller transit times into the mid-latitudinal LMS than into polar LMS is found that is indicative of a separation of the shallow from the deep branch of the residual circulation. This separation between the shallow and the deep circulation branch is further manifested in a distinction in the aspect ratio
\end{abstract}

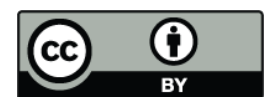

Correspondence to: T. Birner (thomas@atmos.colostate.edu) of the vertical to meridional extent of the trajectories, the integrated mass flux along the residual circulation trajectories, as well as the stratospheric entry latitude of the trajectories. The residual transit time distribution reproduces qualitatively the observed seasonal cycle of youngest air in the extratropical LMS in fall and oldest air in spring.

\section{Introduction}

The stratospheric part of the residual mean meridional mass circulation (stratospheric residual circulation for short hereafter) transports air from the tropical tropopause to extratropical latitudes. Here, the term residual circulation is to be interpreted in its usual Transformed Eulerian Mean (TEM) sense (see Sect. 2 for more details) which represents an approximation of the diabatic or Lagrangian mean circulation. Overall this circulation is described by tropical upwelling, poleward flow, and extratropical downwelling (e.g. Shepherd, 2007). The bulk of this circulation is driven by breaking extratropical planetary waves - often referred to as the extratropical pump (Holton et al., 1995). In the lowermost stratosphere (LMS), synoptic-scale baroclinic eddies that break just above the subtropical jet also contribute to this wave driven circulation (Held and Hoskins, 1985; Plumb, 2002; Shepherd, 2007). One may therefore distinguish two separate branches of the stratospheric residual circulation - a deep branch driven by planetary waves and a shallow branch driven by synoptic and planetary scale waves (Plumb, 2002).

In the present study we seek to derive objective ways to distinguish these two circulation branches and thereby ask whether the picture of two well separated circulation branches is sensible. This is done by studying residual

Published by Copernicus Publications on behalf of the European Geosciences Union. 
circulation trajectories, i.e. trajectories along the (timedependent) residual streamfunction. Characteristics of these trajectories, such as their dominant pathways and associated transit times from the tropical tropopause to a given arrival point prove useful as descriptors of the stratospheric residual circulation in addition to the traditional description by the (seasonal-mean) residual streamfunction. As far as we are aware, this approach has been used first by Rosenlof (1995) and the derived residual circulation transit time has been used as a proxy for age of air. The approach has received relatively little attention since then, mostly due to the more accurate description of stratospheric transport by age of air and related concepts based on full three dimensional transport (see below). Here, our goal is not to derive a proxy of age of air based on residual circulation trajectories. Rather, our goal is to use diagnostics derived from residual circulation trajectories to better understand structural characteristics of the stratospheric residual circulation.

The term stratospheric residual circulation in this study is distinguished from the Brewer-Dobson circulation (Brewer, 1949; Dobson et al., 1929) which refers to the chemical transport circulation of the stratosphere. The Brewer-Dobson circulation includes mean mass transport and two-way mixing, only the former is related to the residual circulation (see e.g. the glossary in Shepherd, 2002). Two-way mixing by definition does not lead to net mass exchange but may lead to net tracer exchange if the tracer exhibits a background gradient. That said, we do not intend to advocate different notional Brewer-Dobson circulations for different chemical tracers, but rather to underline the crucial distinction between the net transport of mass and chemical tracers.

Stratospheric transport is often described through the concept of (mean) age of air (Waugh and Hall, 2002). This concept takes advantage of the fact that most air entering the stratosphere does so through the tropical tropopause. The mean age of (stratospheric) air at a given position and time is then given by the mean transit time of air traveling from the tropical tropopause to that position. It is important to note, that age of air inherently includes the transport effects of both the residual (mass) circulation and two-way mixing. Dominant transport pathways have been studied numerous times within the age of air framework (e.g. Hall, 2000; Douglass et al., 2008; Reithmeier et al., 2008). In the present study we will focus on the conceptually simpler framework of (hypothetical) transport by the residual circulation alone. Diagnostics related to this residual circulation transport are conceptually distinct from diagnostics related to the full transport residual circulation transit times should therefore not be confused with age of air.

A recent study by Bönisch et al. (2009) found a seasonal cycle with oldest mean age of air during spring and youngest mean age of air during fall in the upper part of the midlatitudinal LMS $(\sim 360 \mathrm{~K})$ derived from in-situ $\mathrm{SF}_{6}$ measurements (cf. similar results from the trajectory studies by Berthet et al. (2007); Hoor et al. (2010) and the $\mathrm{O}_{3}-\mathrm{N}_{2} \mathrm{O}$ cor- relation analysis by Hegglin and Shepherd (2007)). Furthermore, they used simultaneous measurements of $\mathrm{SF}_{6}$ and $\mathrm{CO}_{2}$ to calculate tracer transit times (resulting from residual circulation transport and two-way mixing) from the tropical upper troposphere to the extratropical LMS. These tracer transit times were found to be shortest for arrivals during summer and fall and longest for arrivals during spring. Bönisch et al. (2009) speculated that these seasonal cycles maybe at least partially explained by the seasonal cycle in both branches of the circulation, as opposed to by the effects of two-way mixing alone. Whereas the deep circulation branch is most active during winter and spring and becomes almost inactive during summer, the shallow circulation branch is active during all seasons with strongest wave forcing during winter and spring. One therefore expects age of air in the extratropical LMS to be more strongly influenced by the deep circulation branch during winter and spring whereas age of air should be predominantly influenced by the shallow circulation branch during summer and fall. This speculation will be studied in more detail in the present study. It will be shown that transit times into the mid-latitudinal LMS along the residual circulation are indeed longest during spring and shortest during fall, in qualitative agreement with the observations in Bönisch et al. (2009).

The paper is organized as follows. Section 2 describes the data sets and methods used, Sect. 3 presents the results, and Sect. 4 summarizes and concludes the paper.

\section{Data and methodology}

Most results in this study are based on a three-year integration with the Canadian Middle Atmosphere Model (CMAM) after spin-up (sea-surface temperatures are annually repeating, interannual variability is therefore small). This integration is identical to the one described in Birner (2010). CMAM represents a comprehensive chemistry climate model (Beagley et al., 1997; Scinocca et al., 2008). The configuration used here corresponds to T47 spectral horizontal resolution and 71 vertical levels that extend up to around $100 \mathrm{~km}$ altitude. For comparison, data from the ECMWF reanalysis product ERA40 (Uppala et al., 2005) and the Japanese reanalysis JRA25 (Onogi et al., 2007) - are used.

The residual circulation is defined in the Transformed Eulerian Mean (TEM) sense (Andrews et al., 1987). That is, the residual (mass) streamfunction in pressure coordinates is defined through

$\Psi^{*} \equiv \Psi-a g^{-1} \cos \varphi \frac{\overline{v^{\prime} \Theta^{\prime}}}{\partial_{p} \bar{\Theta}}$,

where formally $\Psi \equiv a g^{-1} \cos \varphi \int_{\mathrm{TOA}}^{p} \bar{v} d p^{\prime}$ is the conventional (mass) streamfunction in pressure coordinates (TOA denotes top of the atmosphere), and overbars denote zonal averages. The procedure for computing $\Psi$ here follows Juckes (2001), 
see also Iwasaki (1989), i.e. the vertically integrated meridional mass flux above a given model level $\eta$ is first obtained by calculating $\int_{\mathrm{TOA}}^{\eta} v \partial_{\eta} p d \eta^{\prime}$. This quantity is then interpolated onto pressure surfaces and the zonal average is taken in these pressure coordinates, which when scaled by $\mathrm{ag}^{-1} \cos \varphi$ gives $\Psi$.

The resulting meridional and vertical residual velocities in pressure coordinates are

$\bar{v}^{*}=g(a \cos \varphi)^{-1} \partial_{p} \Psi^{*} \quad$ and $\quad \bar{\omega}^{*}=-g(a \cos \varphi)^{-1} \partial_{\varphi} \Psi^{*}$.

Note that the way the residual velocity components are computed here differs slightly from Andrews et al. (1987) mainly in that $\bar{\omega}$ does not enter the computation. Instead, $\bar{\omega}^{*}$ is obtained through mass balance from $\bar{v}^{*}$. For reference, the middle-atmospheric seasonal mean residual stream function $\Psi^{*}$ is shown in Fig. 1 (top) for boreal winter (DJF) and boreal summer (JJA) from CMAM.

In this study trajectory calculations are carried out in the latitude-altitude plane driven by $\bar{v}^{*}$ and $\bar{\omega}^{*}$ as defined above. In order to have smoothly varying velocity fields in time, monthly averages of $\bar{v}^{*}$ and $\bar{\omega}^{*}$ are used. Daily velocity fields are then obtained from the monthly averaged fields through linear interpolation. A test with daily residual velocity fields resulted in very small sensitivity of the results to this higher temporal resolution of the velocity fields.

Transit times along the residual circulation trajectories refer to the time elapsed since air has entered the stratosphere through the tropical tropopause. These transit times are obtained by running backward trajectories from a given latitude and pressure until the trajectory crosses the tropopause (here defined as the thermal tropopause). The location where the backward trajectory crosses the tropopause defines the stratospheric entry point in a forward sense (which will be located in the tropics in almost all cases, see below). Different diagnostics to describe these backward residual circulation trajectories will be used, such as the transit time, minimum pressure encountered (alternatively, the maximum altitude), minimum and maximum latitudes encountered, stratospheric entry latitudes, etc. Some of these diagnostics have been used by Rosenlof (1995) and similar diagnostics have been applied to full 3-d transport calculations by e.g. Hall (2000); Reithmeier et al. (2008).

\section{Results}

The structure of the residual streamfunction in Fig. 1 (top) suggests that the residual circulation is composed of two major branches: one branch extending deep into the middle atmosphere and a shallower branch in the lowest part of the stratosphere. Given that vertical velocities are much smaller than meridional velocities one expects transit times along the residual streamfunction to be much longer for the deep than for the shallow branch. This is confirmed in Fig. 1 (bottom) which shows these transit times corresponding to the frozenin seasonal mean residual streamfunction shown in the top part of that figure. Transit times corresponding to the shallow branch of the circulation are typically less than one year whereas they are on the order of a few years along the deep branch of the circulation. In general, transit times seem to largely depend on the minimum pressure visited by a given trajectory.

For transit times longer than a few months frozen-in seasonal mean residual velocities are clearly not appropriate, at most for conceptual purposes. Figure 2 shows similarly obtained transit times, but along time-dependent, annually repeating residual streamlines. In this case, backward trajectories were started at latitudes poleward of $30^{\circ}$ on 15 January and $15 \mathrm{July}$ and at a pressure corresponding to $\Theta_{\mathrm{TP}}+30 \mathrm{~K}$ which roughly corresponds to the top of the ExTL (e.g. Hoor et al., 2004; Hegglin et al., 2009), i.e. it corresponds to the lowest level above the extratropical tropopause which is not heavily influenced by local, i.e. extratropical, STE. Again, transit times corresponding to the shallow branch of the residual circulation are on the order of one year or less whereas they are on the order of a few years along the deep branch of the residual circulation.

\subsection{Annual mean transit times}

In order to evaluate the overall distribution of transit times to various places in the global latitude-altitude plane, backward trajectories have been run along the time-dependent, annually repeating residual streamfunction, starting at many different pressure levels above the local tropopause at all latitudes and at 5 day intervals throughout the year. Figure 3 (left) shows the resulting annual mean distribution of the residual circulation transit time and the strength of its meridional gradient for CMAM. Transit times of about one year or less are found in the tropical stratosphere and in the lower mid-latitudinal stratosphere equatorward of about $60^{\circ}$. In contrast, transit times are much higher, on the order of several years, throughout the high-latitude stratosphere, with the highest transit times of 4-5 years in the lowest stratosphere above the poles. A strong meridional gradient between $\sim 60-70^{\circ}$ and below $\sim 50 \mathrm{hPa}$ exists that supports the notion of two well separated branches of the residual circulation. Note that age of air shows the opposite behaviour with very weak meridional gradients in the lowest stratosphere and larger meridional gradients higher in the stratosphere (due to the polar vortex edge acting as a mixing barrier, e.g. Waugh and Hall, 2002; Reithmeier et al., 2008).

The structure of the corresponding minimum pressure visited by the trajectories further supports the notion of two well separated circulation branches (Fig. 3, right). Shorter transit times correspond to higher minimum pressures, consistent with the shallow branch of the circulation. Longer transit times correspond to lower minimum pressures, consistent with the deep branch of the circulation. In general, 

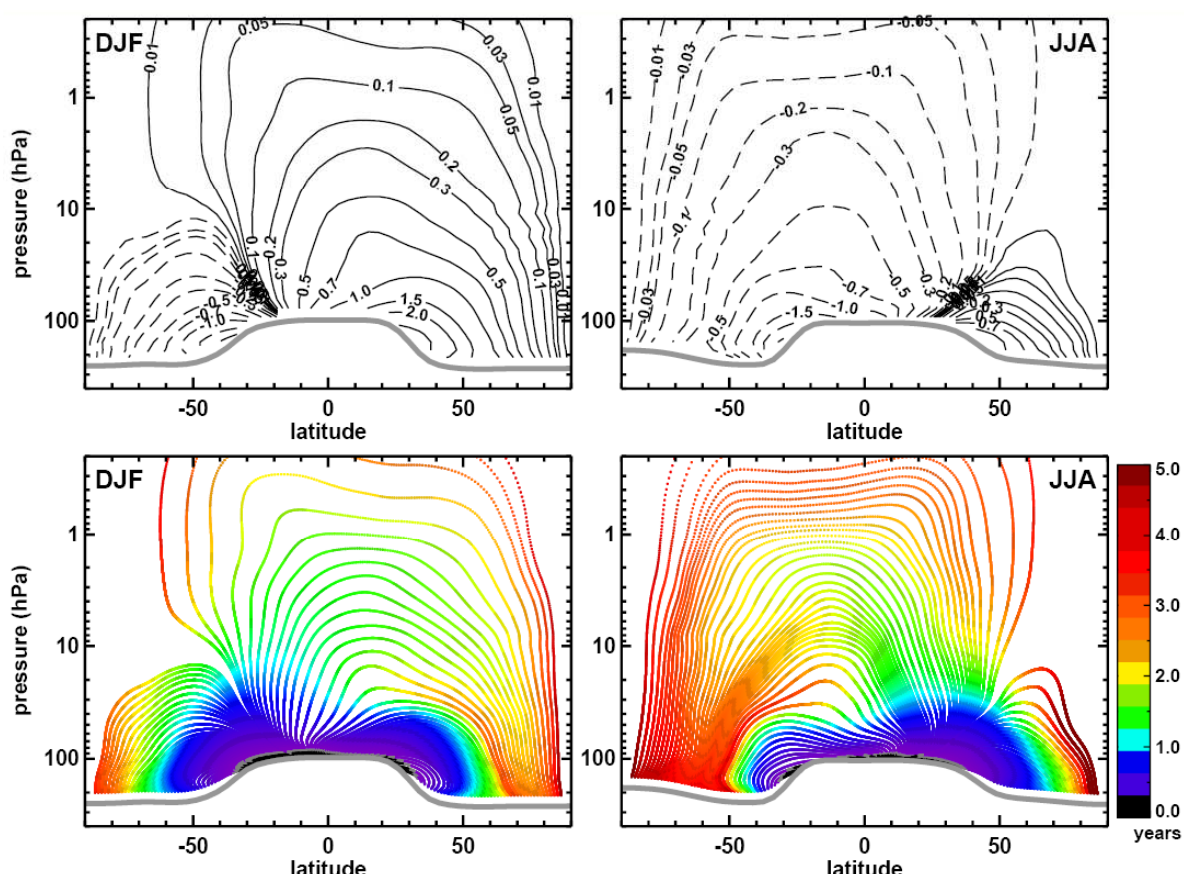

Fig. 1. (Top) Seasonal mean residual streamfunction (divided by $a$, in $10^{2} \mathrm{~kg} / \mathrm{m} / \mathrm{s}$, negative values dashed) for CMAM. Note irregularly spaced contours. (bottom) Trajectories along fixed residual streamlines and their associated transit times (colour coding, years). Only trajectories arriving poleward of $30^{\circ}$ are plotted. Left panels: boreal winter, right panels: boreal summer. Thick gray lines mark average tropopause pressure in all panels.
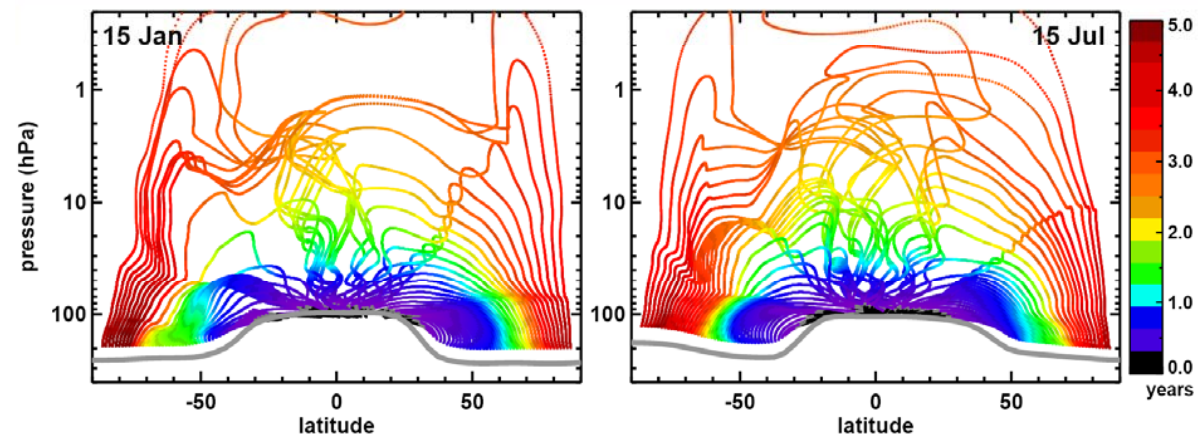

Fig. 2. Trajectories along time-dependent annually repeating residual streamlines and their associated transit times (colour coding, years) for CMAM. Trajectories were run backward starting at arrival latitudes poleward of $30^{\circ}$ on 15 January (left) and 15 July (right) and were terminated when they crossed the tropopause. Arrival pressure is set to correspond to $\Theta_{\mathrm{TP}}+30 \mathrm{~K}$ (roughly the top of the ExTL). Thick gray lines mark average tropopause pressure for given date.

trajectories arriving equatorward of about $60^{\circ}$ did not visit pressures lower than about $70 \mathrm{hPa}$. A strong meridional gradient can again be identified in the lowest stratosphere between $\sim 60-70^{\circ}$. These results are qualitatively consistent with earlier results by Rosenlof (1995) based on trajectories driven by zonal mean diabatic heating rates from meteorological analyses.

Figure 4 shows corresponding results for JRA25 (top) and ERA40 (bottom) for the period 1979-2001. As for CMAM monthly climatologies for $\bar{v}^{*}$ and $\bar{\omega}^{*}$ have been used to compute backward trajectories along residual streamlines. Mete- orological analyses are known to be biased toward low age of air due to enhanced dispersion by the data assimilation process (Monge-Sanz et al., 2007). Figure 4 confirms this expectation, somewhat more so for ERA40 than for JRA25. Transit times along the residual streamlines are generally smaller for ERA40 and JRA25 that for CMAM, especially in the polar regions. It is important to note that transit times here do not include the effect of two-way mixing. It can be concluded that the residual circulation in the reanalyses is biased fast compared to CMAM. 

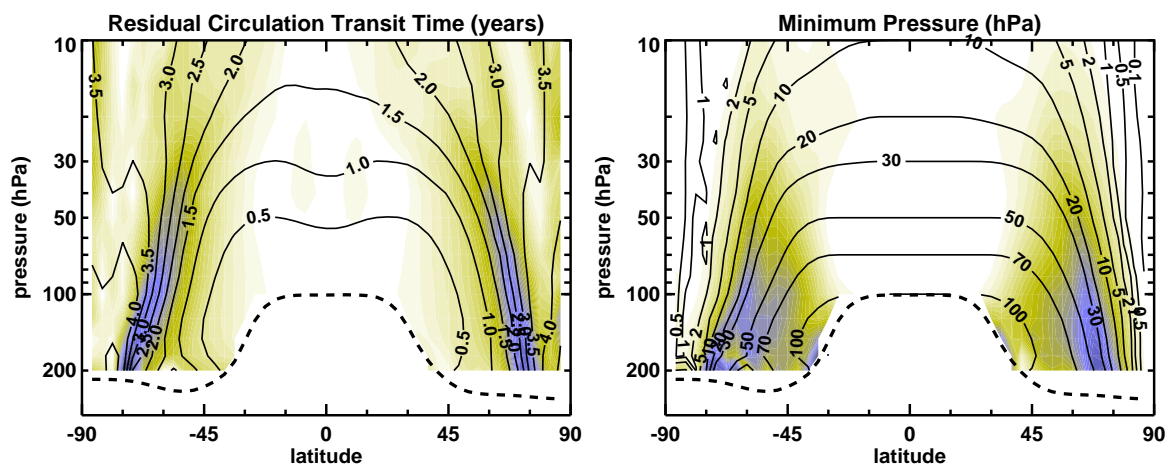

Fig. 3. Black contours: annual mean transit time (left, in years) and minimum pressure visited (right, in hPa) of trajectories along timedependent annually repeating residual streamlines from CMAM. The background color shading quantifies the absolute value of the meridional gradient of the displayed fields (in arbitrary units, darker shading for larger gradients, blue for largest gradients). Thick dashed lines mark average position of the tropopause.
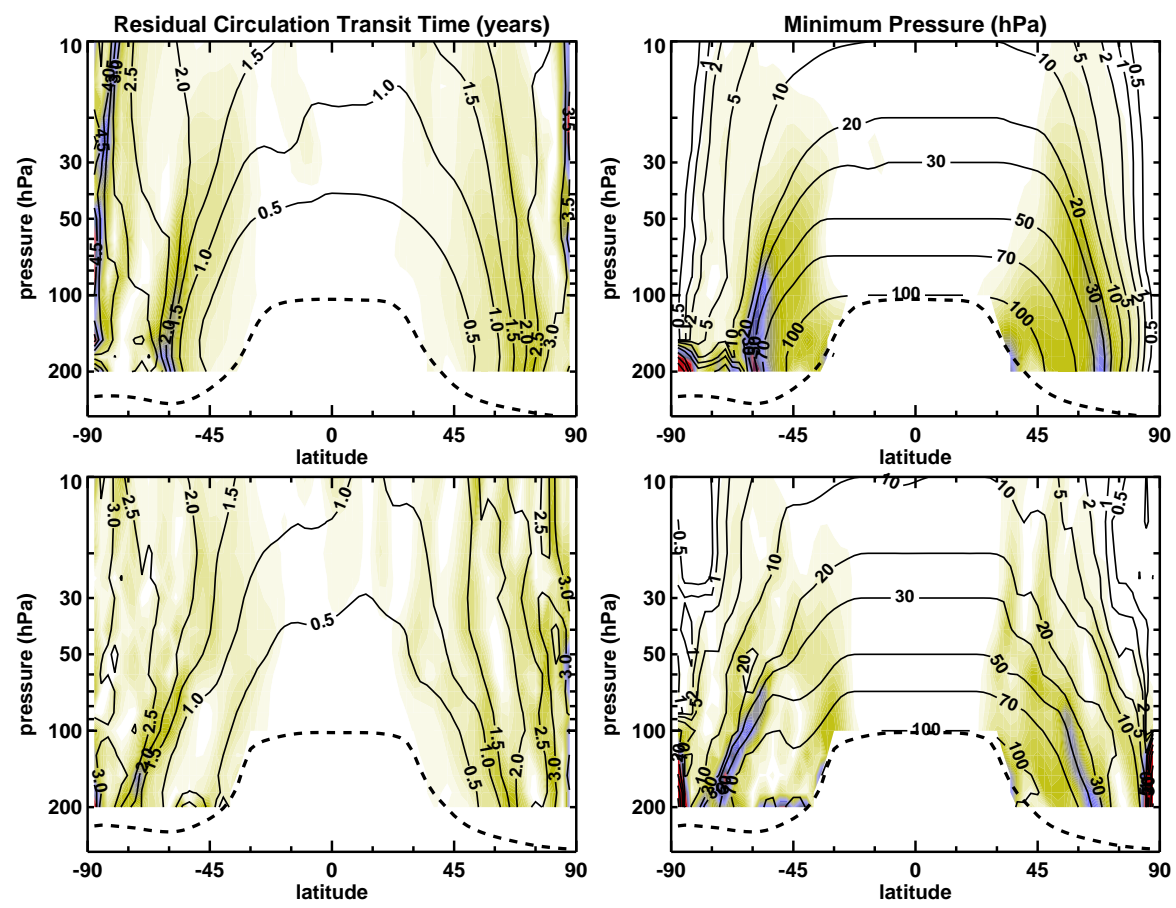

Fig. 4. As Fig. 3 but for JRA25 (top) and ERA40 (bottom) for 1979-2001 (same units for color shading).

The minimum pressure visited by the trajectories agrees well between JRA25 (Fig. 4, top right) and CMAM (Fig. 3, right), ERA40 (Fig. 4, bottom right) also agrees qualitatively in this measure. Strong meridional gradients in the transit times and minimum pressures between $\sim 60-70^{\circ}$ are also found for JRA25. ERA40 does not show these gradients as clearly.

Preliminary results using the more recently compiled ERA interim reanalysis product (Simmons et al., 2007), which employs $4 \mathrm{dVar}$ data assimilation as opposed to the older $3 \mathrm{dVar}$ system employed in ERA40, show much improved mini- mum pressures and transit times along residual circulation trajectories that are in remarkable agreement with those from CMAM.

\subsection{Distinguishing shallow from deep circulation branch}

The results thus far indicate a distinction between two separate stratospheric circulation branches: a shallow branch characterized by comparably fast turnover time-scales (small transit times) and a deep branch characterized by comparably 

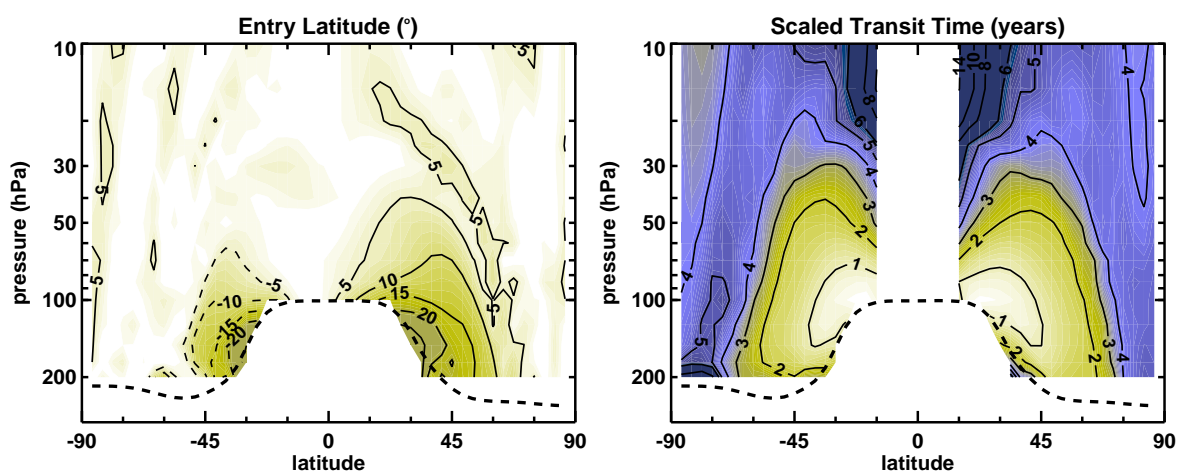

Fig. 5. Annual mean stratospheric entry latitude (left, in degrees, southern latitudes dashed, zero contour omitted) and scaled transit time (right, in years) of residual circulation trajectories from CMAM. The scaling used on the right is given by $90^{\circ} /\left|\varphi_{a}-\varphi_{e}\right|$, where $a$ and $e$ refer to arrival and entry latitudes, respectively. In the tropics, $\varphi_{a} \approx \varphi_{e}$, which results in exceedingly large values - the region equatorward of $15^{\circ}$ is therefore omitted on the right. Thick dashed lines mark average position of the tropopause.

slow turnover time-scales (large transit times). This distinction is now further quantified.

Transit times along the (time-dependent) residual streamlines are one way to characterize the circulation. Other characteristics include the vertical and latitudinal extent of a given trajectory. The vertical extent is strongly related to the minimum pressure visited by the trajectories which has already been discussed above. The latitudinal extent is strongly related to the stratospheric entry latitude (at the tropical tropopause) at a given arrival latitude. Annual mean values of this stratospheric entry latitude are shown in Fig. 5 (left), obtained from the same backward trajectories as used in the previous section for CMAM. Evidently, trajectories within the deep circulation branch enter the stratosphere almost exclusively within $5^{\circ}$ of the equator. On the other hand, trajectories within the shallow circulation branch enter the stratosphere closer to the poleward flanks of the tropics.

The distinction between the two stratospheric circulation branches in terms of the stratospheric entry latitudes can be used to define a scaled residual circulation transit time with a scale factor inversely proportional to the latitudinal extent. We choose a scale factor of $90^{\circ} /\left|\varphi_{a}-\varphi_{e}\right|$, where subscripts $a$ and $e$ refer to arrival and entry latitudes, respectively. The denominator of this scale factor represents a proxy for the latitudinal extent of the trajectories, whereas the numerator $\left(90^{\circ}\right)$ represents a proxy for the maximum possible latitudinal extent.

Figure 5 (right) shows annual mean values of the resulting scaled transit time. Note that $\varphi_{a} \approx \varphi_{e}$ in the tropics, which results in exceedingly large scaled transit time values - the region equatorward of $15^{\circ}$ is therefore omitted. The vertical and meridional distribution of this scaled transit time is indicative of two distinct regimes corresponding to the two distinct circulation branches: one in the subtropics and midlatitudes below $\sim 30-50 \mathrm{hPa}$ with scaled transit times generally less than $2 \mathrm{yr}$, and one poleward and upward of this region with scaled transit times between 4-5 yr.
Vertical and horizontal extents of the trajectories can also be combined to form an aspect ratio. The shallow circulation branch should have a much smaller aspect ratio of vertical to horizontal extent of the trajectories than the deep circulation branch. This aspect ratio is defined here as:

$r \equiv \frac{\Delta z}{\Delta y}=\frac{H \ln \left(p_{\max } / p_{\min }\right)}{a\left(\varphi_{\max }-\varphi_{\min }\right)}$,

where subscripts max and min refer to the maximum and minimum pressure or latitude encountered along the trajectory, $H=6 \mathrm{~km}$ is the scale height, and $a$ is the radius of the earth. Given the shallowness of the earth's atmosphere we expect this aspect ratio to be roughly of order $10^{-3}$.

Figure 6 (top, left) shows the annual mean aspect ratio $r$ as a function of arrival latitude and pressure. A distinction between the shallow and the deep circulation branches is evident with small aspect ratios of $r \lesssim 1 \times 10^{-3}$ for the shallow branch and much larger aspect ratios for the deep branch (a factor of 3 or more larger than for the shallow branch - note the logarithmic color scale in the figure). In the tropics the predominant upward motion shows up in increasing $r$ with altitude. Similar results are obtained for JRA25 and ERA40 with these reanalyses somewhat underestimating the higher aspect ratios of the deep branch.

Another way to distinguish the shallow from the deep branch of the circulation is to quantify the integrated mass flux along the residual streamlines:

$M \equiv \int_{\left(\varphi_{e}, p_{e}\right)}^{\left(\varphi_{a}, p_{a}\right)} \rho \overline{\boldsymbol{v}}^{*} \cdot d \boldsymbol{s}$,

where $\rho$ is density, $\overline{\boldsymbol{v}}^{*} \equiv\left(\bar{v}^{*}, \bar{w}^{*}\right), d \boldsymbol{s} \equiv(d y, d z)$, and subscripts $e$ and $a$ refer to entry and arrival points, respectively. As before, $z$ is approximated as a log-pressure height, i.e. $d z=-H d \ln p$, and therefore $\bar{w}^{*}=-(H / p) \bar{\omega}^{*}$ and $\rho=$ $p /(g H)$.

Figure 6 (bottom, left) shows the annual mean integrated mass flux $M$ as a function of arrival latitude and pressure 

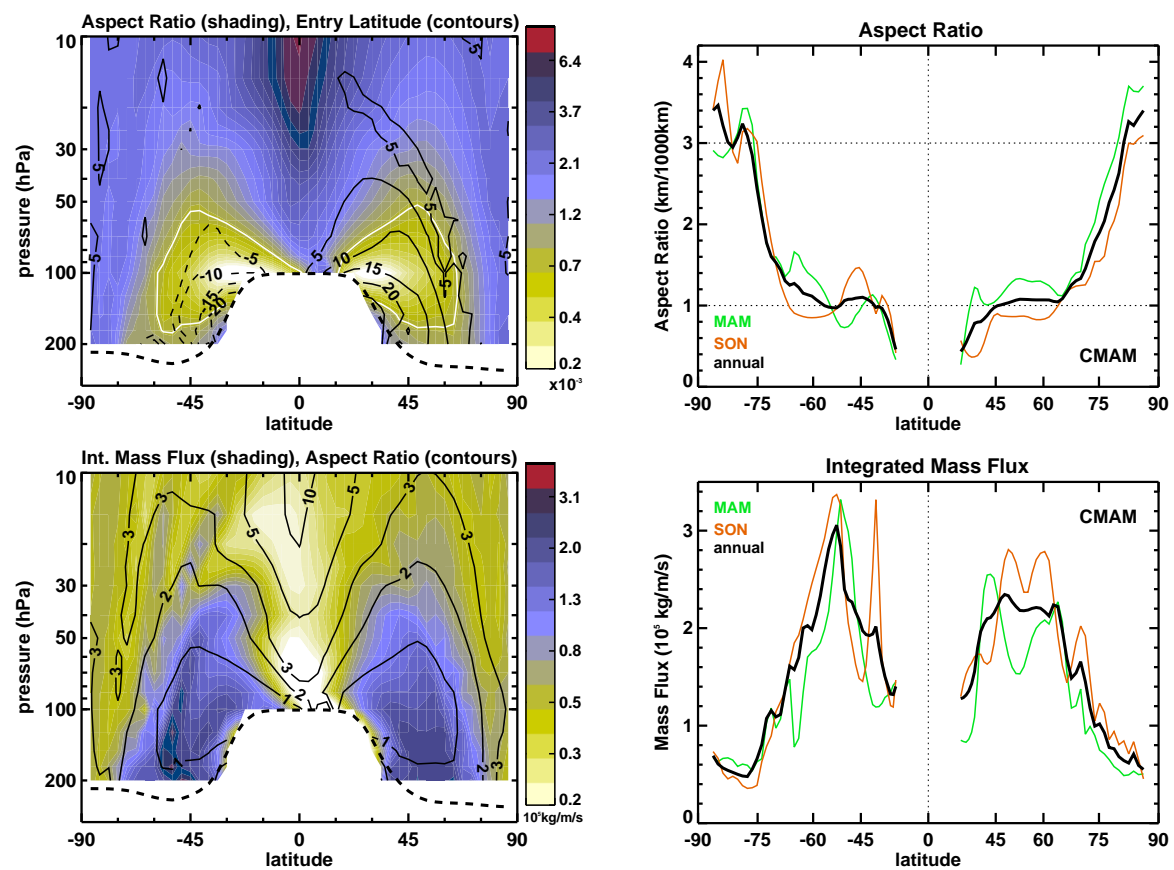

Fig. 6. Trajectory vertical to horizontal aspect ratio $r\left(\mathrm{~km}\right.$ per $1000 \mathrm{~km}$, top) and integrated mass flux along trajectories (in $10^{5} \mathrm{~kg} / \mathrm{m} / \mathrm{s}$, bottom) for CMAM. Left: annual means as a function of arrival pressure and latitude (color shading, note logarithmic scale). Stratospheric entry latitudes (contours, in degrees, southern latitudes dashed, zero contour omitted) and the contour $r=1 \times 10^{-3}$ (white) are overplotted in the top. Annual mean trajectory aspect ratio $r$ (contours, in km per $1000 \mathrm{~km}$, note irregular contour spacing) are overplotted in the bottom. Right: as a function of arrival latitude with arrival pressure set to correspond to $\Theta_{\mathrm{TP}}+30 \mathrm{~K}$ (roughly the top of the ExTL). Note stretched abscissa, which is proportional to $\cos \varphi$ to highlight extratropical areas (tropical values, equatorward of $30^{\circ}$, are omitted). Green: boreal spring, brown: boreal autumn, black: annual mean.

for CMAM. The shallow circulation branch (regions of small aspect ratio $r$ ) is associated with much higher values for $M$ than the deep circulation branch (regions of large aspect ratio $r$ ). It is important to note that both the average strength of the mass flux along the residual streamlines and the length of the residual transport pathway contribute to $M$. The mass flux contribution is larger for the shallow circulation branch whereas the path-length contribution is larger for the deep circulation branch. Apparently, the mass flux contribution dominates over the path length contribution to make $M$ larger for the shallow circulation branch.

The right panels of Fig. 6 show the aspect ratio $r$ (top) and integrated mass flux $M$ (bottom) as a function of arrival latitude for trajectories arriving $30 \mathrm{~K}$ above the local tropopause (at the top of the ExTL). Two seasons - northern spring and northern fall - are contrasted with the annual mean (these seasons strictly refer to the arrival latitudes, trajectories arriving at those latitudes still underwent seasonal changes). The overall characteristics of small $r$ and large $M$ for the shallow circulation branch and larger $r$ and smaller $M$ for the deep circulation branch are again evident. Interestingly, the shallow circulation branch signature shows up as a plateau-like region in mid-latitudes with $r \sim 1 \times 10^{-3}$ and $M \gtrsim 2 \times 10^{5} \mathrm{~kg} / \mathrm{m} / \mathrm{s}$, especially in the Northern Hemi- sphere. Another plateau-like region exists close the poles with $r \sim 3 \times 10^{-3}$ and $M<1 \times 10^{5} \mathrm{~kg} / \mathrm{m} / \mathrm{s}$.

In the extratropics the aspect ratio undergoes a seasonal cycle with smallest values during fall and largest values during spring (somewhat more pronounced in the Northern Hemisphere, consistent with the stronger seasonality of the subtropical jet there). The integrated mass flux undergoes a seasonal cycle with largest values during fall and smallest values during spring. These seasonal cycles of $r$ and $M$ suggest smaller transit times predominantly along the shallow branch for trajectories arriving in the extratropics during fall and larger transit times with a stronger influence of the deep branch for trajectories arriving in the extratropics during spring. These characteristics of the annual cycle will now be discussed in more detail.

\subsection{Seasonal cycle of transit times}

Figures 7 and 8 show the annual cycle of the relative percentage deviations of transit times (left) and aspect ratios (right) from their annual mean as a function of arrival latitude for the northern and southern hemispheric extratropics, respectively. Relative deviations are displayed as opposed to absolute deviations in order to not obscure the picture by 

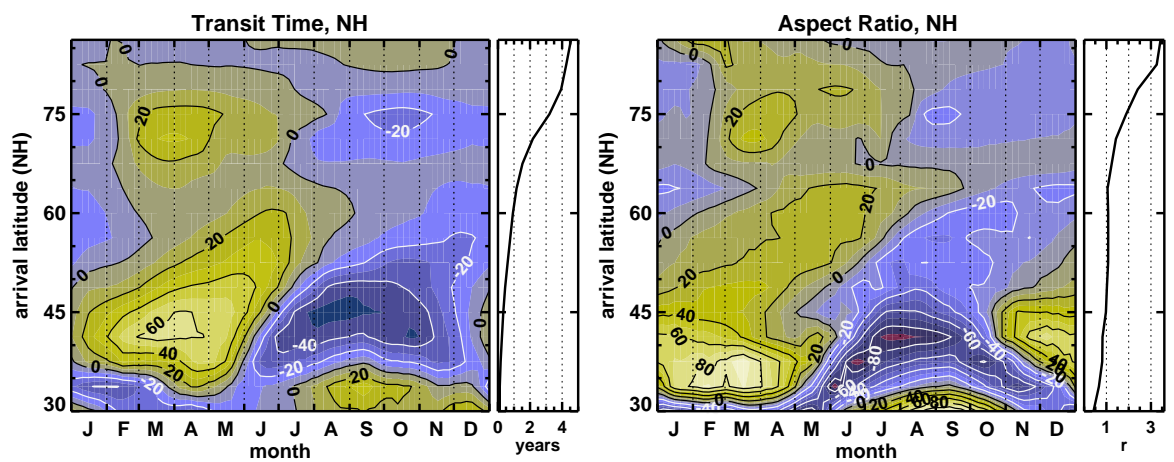

Fig. 7. Annual cycles of residual circulation transit times (left) and of trajectory vertical to horizontal aspect ratio $r$ (right) for northern hemispheric extratropics as a function of arrival latitude for CMAM (plotted are percentage deviations from annual mean). Arrival pressure is set to correspond to $\Theta_{\mathrm{TP}}+30 \mathrm{~K}$. Annual mean curves are shown in the small right-hand panels (dotted lines mark integer values).
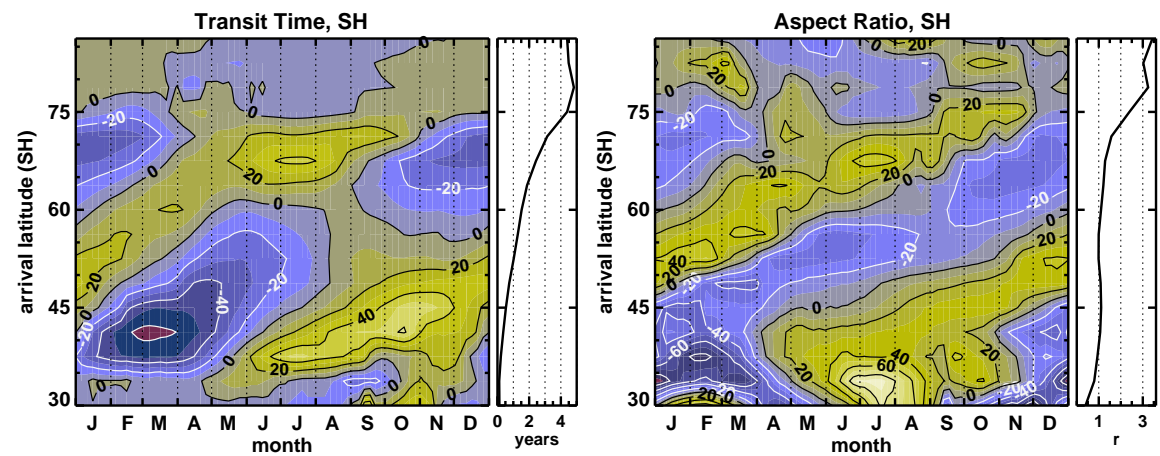

Fig. 8. Same as Fig. 7 but for southern hemispheric extratropics.

the strong latitudinal gradients in the annual mean values. Note that these annual cycles strictly refer to the arrival locations whereas the trajectories along the residual streamlines are still allowed to undergo seasonal changes.

The strongest annual cycle in transit times exists in midlatitudes $\left(\sim 40-45^{\circ}\right)$, with maximum relative deviations from the annual mean exceeding 50\%. Transit times are largest during late winter and spring and smallest during late summer and fall there. Further poleward this annual cycle propagates toward later seasons with maximum transit times reaching early summer and minimum transit times reaching early winter around $60^{\circ}$. The latitude range of large seasonal relative deviations in transit times from the annual mean roughly coincides with the latitude range of large seasonal relative deviations in the aspect ratio $r$ from the annual mean. This suggests that it is in particular the shallow circulation branch that causes these strong seasonal variations. The behavior poleward of $\sim 60^{\circ}$ confirms this picture: transit times and trajectory aspect ratio in high latitudes are mainly controlled by the deep circulation branch with a much weaker annual cycle (in terms of relative deviations - absolute deviations are largest in high latitudes due to the large annual mean values there), and large annual mean transit times and trajectory aspect ratio.
Tropical control with transit times $\sim 1-2$ months reaches out to around $30-35^{\circ}$ latitude in each hemisphere (Fig. 9, left). Transit times reach minimum values during northern winter in the southern tropics and during southern winter in the northern tropics (note the hemispheric asymmetry in annual mean transit times). These annual variations are consistent with maximum tropical upwelling shifted into the respective summer hemisphere (e.g. Butchart et al., 2006). Transit times reach a maximum relative deviation of $\sim 40 \%$ above their annual mean value roughly over the equator during southern spring, consistent with the hemispheric asymmetry in wave driving and the corresponding annual cycle in maximum tropical upwelling (Yulaeva et al., 1994).

The aspect ratio shows exceedingly large values over the latitudes and times of maximum tropical upwelling (Fig. 9, right), consistent with an almost vanishing horizontal trajectory component there. The general correspondence of smaller aspect ratios with shorter transit times and larger aspect ratios with longer transit times is also confirmed in the tropics. 

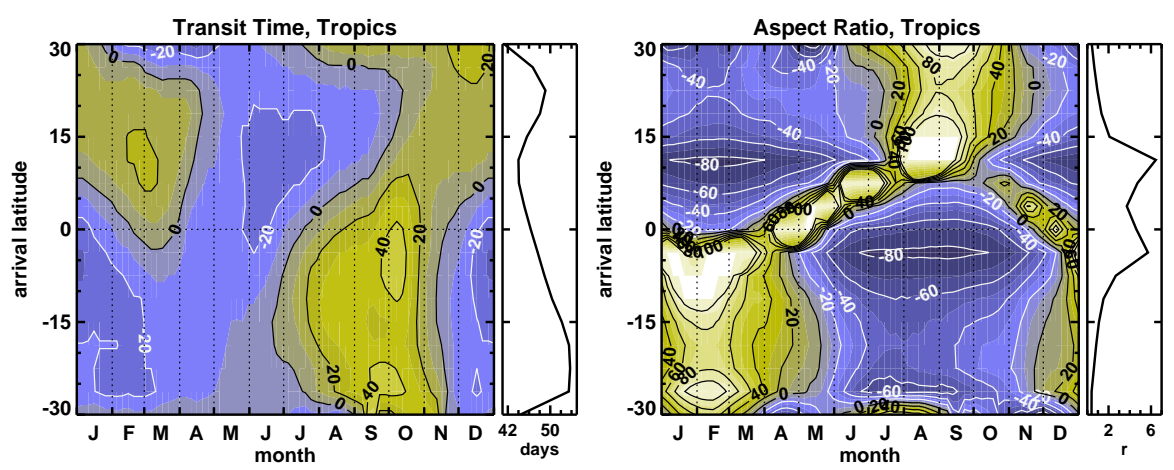

Fig. 9. Same as Fig. 7 but for the tropics. Note annual mean transit times are given in days here. Contours and color shading are limited to less than $100 \%$ in the case of the aspect ratio (right). Latitudes and times of exceedingly large aspect ratio mark maximum tropical upwelling there (i.e. corresponding trajectories have an almost vanishing horizontal range).
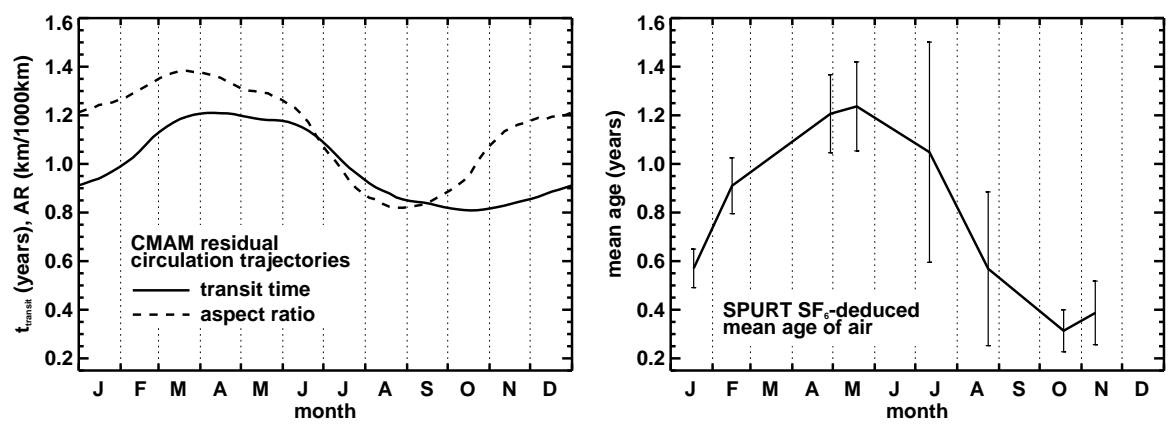

Fig. 10. Left: annual cycles of residual circulation transit time (full line, years) and trajectory aspect ratio $r$ (dashed line, $\mathrm{km}$ per $1000 \mathrm{~km}$ ) averaged over $\left[40^{\circ} \mathrm{N}, 80^{\circ} \mathrm{N}\right]$ for CMAM. Arrival pressure is set to correspond to $\Theta_{\mathrm{TP}}+30 \mathrm{~K}$. Right: annual cycle of $\mathrm{SF}_{6}-\mathrm{deduced} \mathrm{mean}$ age of air from SPURT averaged over equivalent latitudes $\left[40^{\circ} \mathrm{N}, 80^{\circ} \mathrm{N}\right]$ and $\left[\Theta_{\mathrm{TP}}+25 \mathrm{~K}, \Theta_{\mathrm{TP}}+35 \mathrm{~K}\right]$ (data identical to that used in Bönisch et al., 2009).

\section{Summary and conclusions}

The stratospheric part of the residual mean meridional mass circulation was studied using trajectories along the (timedependent) residual circulation streamfunction. These residual circulation trajectories were described primarily through associated transit times from their stratospheric entry point at the tropical tropopause to a given arrival location and time of the year, as well as through the range in altitude and latitude visited by the trajectories (including the trajectory aspect ratio $r=\Delta z / \Delta y$ ). A scaled transit time was defined using a scale factor of $90^{\circ} /\left|\varphi_{a}-\varphi_{e}\right|$, where $\varphi_{a}$ and $\varphi_{e}$ are the arrival and entry latitudes, respectively.

A separation was found between a shallow and a deep branch of the stratospheric residual circulation. The deep branch is characterized by: (1) a tall aspect ratio, (2) transit times of several years (scaled transit times of 4-5 yr), (3) stratospheric entry latitudes close to the equator, and (4) small integrated mass flux. The shallow branch is characterized by: (1) a small aspect ratio, (2) transit times of about one year or less (scaled transit times of 1-2 yr), (3) stratospheric entry latitudes closer to the poleward flanks of the tropics, and (4) large integrated mass flux. Given the meridional extent of the residual circulation trajectories $(\Delta y)$ is essentially constrained by the radius of the earth the aspect ratio of the trajectories is more strongly sensitive to their vertical extent $(\Delta z)$. In this sense it is reasonable to speak of shallow and deep circulation branches.

The residual circulation is a direct consequence of breaking waves and the associated (pseudo-) momentum deposition. In the TEM formalism in steady state this momentum forcing is balanced by the Coriolis torque associated with residual meridional flow. A distinction between different branches of the residual circulation therefore requires distinct regions of wave breaking. In this sense the shallow circulation branch as found in this study is consistent with (Rossby) wave breaking just above the subtropical jet. Planetary and synoptic-scale waves (and gravity waves in the Northern Hemisphere, e.g. Okamoto et al., 2011) contribute to this wave breaking region (McLandress and Shepherd, 2009). On the other hand, the deep circulation branch as found in this study is consistent with planetary-scale waves 
breaking in the middle stratosphere. Synoptic-scale waves are not able to propagate deep into the stratosphere (Charney and Drazin, 1961).

A strong seasonal cycle in residual circulation transit times into the extratropical LMS was found with longest transit times in spring and shortest transit times in fall. This seasonal cycle is consistent with the observed seasonal cycle of mean age of air in the extratropical LMS, as shown in Fig. 10. Residual circulation transit times averaged over 40$80^{\circ} \mathrm{N}$ maximize in April and minimize in October with the aspect ratio preceding this seasonal cycle by 1-2 months. Mean age of air as deduced from $\mathrm{SF}_{6}$ measurements during SPURT (see Bönisch et al., 2009) maximizes in May and minimizes in October. The amplitude of this seasonal cycle of mean age of air is about twice as large as for the residual circulation transit times. Age of air represents a combination of (slow) residual transport and (fast) two-way mixing. Large deviations of the mean age of air from the residual circulation transit times (e.g. during fall) therefore indicate strong influence of two-way mixing.

Breaking Rossby waves lead to both two-way mixing and residual transport. In this sense the seasonality of two-way mixing is coupled to the seasonality of the residual circulation (and vice versa). One may therefore interpret the seasonal variations in residual circulation transit times as simple qualitative description of the seasonal cycle in total transport (despite the apparent large quantitative differences). Diagnostics such as the aspect ratio $r$, the integrated mass flux $M$, and stratospheric entry latitudes $\varphi_{e}$ appear as useful indicators of the distinct effects of the shallow circulation branch compared to the deep circulation branch. Studies of longterm changes in the stratospheric circulation need to take into account the separate effects due to the shallow and deep circulation branches (as recently confirmed by Bönisch et al., 2010).

Acknowledgements. The CMAM runs were completed while TB was with the University of Toronto where James Anstey and Stephen Beagley provided technical help. TB was supported by funding through Colorado State University. HB acknowledges the support by the DFG research group SHARP under grant number EN 367/9-1. We thank the constructive criticism by the anonymous reviewers which lead to significant improvements in the presentation of the material. Free access to ERA40 data, originally generated at ECMWF, was provided through the National Center for Atmospheric Research (NCAR). Access to JRA25 data, originally generated by the cooperative research project of the JRA-25 long-term reanalysis by the Japan Meteorological Agency (JMA) and the Central Research Institute of Electric Power Industry (CRIEPI), was also provided through NCAR.

Edited by: P. Haynes

\section{References}

Andrews, D. G., Holton, J. R., and Leovy, C. B.: Middle Atmosphere Dynamics, Academic Press, 1987.

Beagley, S. R., de Grandpré, J., Koshyk, J., McFarlane, N. A., and Shepherd, T. G.: Radiative-dynamical climatology of the firstgeneration Canadian Middle Atmosphere Model, Atmos.-Ocean, 35, 293-331, 1997.

Berthet, G., Esler, J. G., and Haynes, P. H.: A Lagrangian perspective of the tropopause and the ventilation of the lowermost stratosphere, J. Geophys. Res., 112, D18102, doi:10.1029/2006JD008295, 2007.

Birner, T.: Residual circulation and tropopause structure, J. Atmos. Sci., 67, 2582-2600, 2010.

Bönisch, H., Engel, A., Curtius, J., Birner, Th., and Hoor, P.: Quantifying transport into the lowermost stratosphere using simultaneous in-situ measurements of SF6 and $\mathrm{CO}_{2}$, Atmos. Chem. Phys., 9, 5905-5919, doi:10.5194/acp-9-5905-2009, 2009.

Bönisch, H., Engel, A., Birner, Th., Hoor, P., Tarasick, D. W., and Ray, E. A.: On the structural changes in the Brewer-Dobson circulation after 2000, Atmos. Chem. Phys. Discuss., 10, 28399 28430, doi:10.5194/acpd-10-28399-2010, 2010.

Brewer, A. W.: Evidence for a world circulation provided by the measurements of helium and water vapor distribution in the stratosphere, Q. J. Roy. Meteorol. Soc., 75, 351-363, 1949.

Butchart, N., Scaife, A. A., Bourqui, M., de Grandpré, J., Hare, S. H. E., Kettleborough, J., Langematz, U., Manzini, E., Sassi, F., Shibata, K., Shindell, D., and Sigmond, M.: Simulations of anthropogenic change in the strength of the Brewer-Dobson circulation, Clim. Dyn., 27, 727-741, 2006.

Charney, J. G. and Drazin, P. G.: Propagation of planetary scale disturbances from the lower into the upper atmosphere, J. Geophys. Res., 66, 83-109, 1961.

Dobson, G. M. B., Harrison, D. N., and Lawrence, J.: Measurements of the amount of ozone in the earth's atmosphere and its relation to other geophysical conditions, Proc. Roy. Soc. Series A, 122, 456-486, 1929.

Douglass, A. R., Stolarski, R. S., Schoeberl, M. R., Jackman, C. H., Gupta, M. L., Newman, P. A., Nielsen, J. E., and Fleming, E. L.: Relationship of loss, mean age of air and the distribution of CFCs to stratospheric circulation and implications for atmospheric lifetimes, J. Geophys. Res., 113, D14309, doi:10.1029/2007JD009575, 2008.

Hall, T. M.: Path histories and timescales in stratospheric transport: analysis of an idealized model, J. Geophys. Res., 105, 2281122823, 2000

Hegglin, M. I. and Shepherd, T. G.: $\mathrm{O}_{3}-\mathrm{N}_{2} \mathrm{O}$ correlations from the Atmospheric Chemistry Experiment: Revisting a diagnostic of transport and chemistry in the stratosphere, J. Geophys. Res., 112, D19301, doi:10.1029/2006JD008281, 2007.

Hegglin, M. I., Boone, C. D., Manney, G. L., and Walker, K. A.: A global view of the extratropical tropopause transition layer from Atmospheric Chemistry Experiment Fourier Transform Spectrometer $\mathrm{O}_{3}, \mathrm{H}_{2} \mathrm{O}$, and $\mathrm{CO}$, J. Geophys. Res., 114, D00B11, doi:10.1029/2008JD009984, 2009.

Held, I. M. and Hoskins, B. J.: Large-scale eddies and the general circulation of the troposphere, Adv. Geophys., 28A, 3-31, 1985.

Holton, J. R., Haynes, P. H., McIntyre, M. E., Douglas, A. R., Rood, R. B., and Pfister, L.: Stratosphere-troposphere exchange, Rev. Geophys., 33, 403-439, 1995. 
Hoor, P., Gurk, C., Brunner, D., Hegglin, M. I., Wernli, H., and Fischer, H.: Seasonality and extent of extratropical TST derived from in-situ CO measurements during SPURT, Atmos. Chem. Phys., 4, 1427-1442, doi:10.5194/acp-4-1427-2004, 2004.

Hoor, P., Wernli, H., Hegglin, M. I., and Bönisch, H.: Transport timescales and tracer properties in the extratropical UTLS, Atmos. Chem. Phys., 10, 7929-7944, doi:10.5194/acp-10-79292010, 2010.

Iwasaki, T.: A diagnostic formulation for wavemean flow interactions and Lagrangian-mean circulation with a hybrid vertical coordinate of pressure and isentropes, J. Meteor. Soc. Japan, 67, 293-312, 1989.

Juckes, M.: A generalization of the transformed eulerian-mean meridional circulation, Q. J. Roy. Meteorol. Soc., 127, 147-160, 2001.

McLandress, C. and Shepherd, T. G.: Simulated Anthropogenic Changes in the Brewer-Dobson Circulation, Including Its Extension to High Latitudes, J. Climate, 22, 1516-1540, 2009.

Monge-Sanz, B. M., Chipperfield, M. P., Simmons, A. J., and Uppala, S. M.: Mean age of air and transport in a CTM: Comparison of different ECMWF analyses, Geophys. Res. Lett., 34, L04801, doi:10.1029/2006GL028515, 2007.

Okamoto, K., Sato, K., and Akiyoshi, H.: A study on the formation and trend of the Brewer-Dobson circulation, J. Geophys. Res., in review, 2011.

Onogi, K., Tsutsui, J., Koide, H., Sakamoto, M., Kobayashi, S., Hatsushika, H., Matsumoto, T., Yamazaki, N., Kamahori, H., Takahashi, K., Kadokura, S., Wada, K., Kato, K., Oyama, R., Ose, T., Mannoji, N., and Taira, R.: The JRA-25 reanalysis, J. Meteor. Soc. Japan, 85, 369-432, 2007.

Plumb, R. A.: Stratospheric transport, J. Meteor. Soc. Japan, 80, 793-809, 2002.

Reithmeier, C., Sausen, R., and Grewe, V.: Investigating lower stratospheric model transport: Lagrangian calculations of mean age and age spectra in the GCM ECHAM4, Clim. Dyn., 30, 225$238,2008$.
Rosenlof, K. H.: Seasonal cycle of the residual mean meridional circulation in the stratosphere, J. Geophys. Res., 100, 5173-5191, 1995.

Scinocca, J. F., McFarlane, N. A., Lazare, M., Li, J., and Plummer, D.: Technical Note: The CCCma third generation AGCM and its extension into the middle atmosphere, Atmos. Chem. Phys., 8, 7055-7074, doi:10.5194/acp-8-7055-2008, 2008.

Shepherd, T. G.: Issues in stratosphere-troposphere coupling, J. Meteor. Soc. Japan, 80, 769-792, 2002.

Shepherd, T. G.: Transport in the middle atmosphere, J. Meteor. Soc. Japan, 85B, 165-191, 2007.

Simmons, A., Uppala, S., Dee, D., and Kobayashi, S.: ERAInterim: New ECMWF reanalysis products from 1989 onwards, Newsletter 110, ECMWF, 11 pp., 2007.

Uppala, S. M., Kallberg, P. W., Simmons, A. J., Andrae, U., Bechtold, P., Costa, V. D., M. Fiorino, M., Gibson, J. K., Haseler, J., Hernandez, A., Kelly, G. A., Li, X., Onogi, K., Saarinen, S., Sokka, N., Allan, R. P., Andersson, E., Arpe, K., Balmaseda, M. A., Beljaars, A. C. M., Berg, L. V. D., Bidlot, J., Bormann, N., Caires, S., Chevallier, F., Dethof, A., Dragosavac, M., Fisher, M., Fuentes, M., Hagemann, S., Holm, E., Hoskins, B. J., Isaksen, L., Janssen, P. A. E. M., Jenne, R., McNally, A. P., Mahfouf, J.-F., Morcrette, J.-J., Rayner, N. A., Saunders, R. W., Simon, P., Sterl, A., Trenberth, K. E., Untch, A., Vasiljevic, D., Viterbo, P., and Woollen, J.: The ERA-40 re-analysis, Q. J. Roy. Meteorol. Soc., 131, 2961-3012, 2005.

Waugh, D. W. and Hall, T. M.: Age of stratospheric air: theory, observations, and models, Rev. Geophys., 40, 1010, doi:10.1029/2000RG000101, 2002.

Yulaeva, E., Holton, J. R., and Wallace, J. M.: On the cause of the annual cycle in tropical lower-stratospheric temperatures, J. Atmos. Sci., 51, 169-174, 1994. 